\title{
25 Research Soure \\ Effects of Etomidate Combined With \\ Dexmedetomidine on Adrenocortical Function in \\ Elderly Patients: A Double-Blind Randomized \\ Controlled Trial
}

Fangjun Wang ( $\nabla$ wfjlxy006@nsmc.edu.cn )

The Affiliated Hospital of North Sichuan Medical College

Sisi Zeng

The North Sichuan Medical College

Luyue Gao

The North Sichuan Medical College

Jiabei Li

The North Sichuan Medical College

Na Wang

The North Sichuan Medical College

\section{Research Article}

Keywords: dexmedetomidine, etomidate, propofol, adrenocortical function, elderly

Posted Date: July 12th, 2021

DOI: https://doi.org/10.21203/rs.3.rs-640114/v1

License: (a) (1) This work is licensed under a Creative Commons Attribution 4.0 International License.

Read Full License 


\section{Abstract}

\section{Introduction}

Etomidate has been advocated to be used in anesthesia of the elderly and the critically ill patients due to its faint effect on cardiovascular system. But the dose-dependent suppression of etomidate on adrenal cortex function leads to the limitation of its clinical application. Clinical research shows that dexmedetomidine can reduce the dose requirements for intravenous or inhalation anesthetics and opioids, and the hemodynamics is more stable during the operation. The objective is to observe the effect of etomidate combined with dexmedetomidine on adrenocortical function in elderly patients.

\section{Methods}

180 elder patients scheduled for elective ureteroscopic holmium laser lithotripsy were randomly allocated to PR group anesthetized with propofol- remifentanil, ER group anesthetized with etomidate-remifentanil, and ERD group anesthetized with dexmedetomidine combined with etomidate-remifentanil. Patients in each group whose operation time was less than or equal to $1 \mathrm{~h}$ were incorporated into short time operation group ( $\mathrm{PR}_{1}$ group, $\mathrm{ER}_{1}$ group and $\mathrm{ERD}_{1}$ group), and whose operation time was more than $1 \mathrm{~h}$ were incorporated into long time operation group ( $\mathrm{PR}_{2}$ group, $\mathrm{ER}_{2}$ group and $\mathrm{ERD}_{2}$ group). The values of SBP, DBP, HR and $\mathrm{SpO}_{2}$ were recorded at $\mathrm{T}_{0}, \mathrm{~T}_{1}, \mathrm{~T}_{2}, \mathrm{~T}_{3}, \mathrm{~T}_{4}, \mathrm{~T}_{5}, \mathrm{~T}_{6}$ and $\mathrm{T}_{7}$. The time of operation, the dosage of etomidate and remifentanil administrated during surgery, the time to spontaneous respiration, recovery and extubation, and the duration of stay in the PACU were recorded. The serum cortisol and ACTH concentration was measured at $t_{0}, t_{1}, t_{2}, t_{3}, t_{4}$ and $t_{5}$.

\section{Results}

The dosage of etomidate was significantly lower in $E R D_{1}$ group and $E R D_{2}$ group compared with $E R_{1}$ group and $\mathrm{ER}_{2}$ group $(P<0.05)$, respectively. The $\mathrm{SBP}$ in $\mathrm{ER}_{2}$ and $\mathrm{ERD}_{2}$ group were higher at $\mathrm{T}_{1}$ and $\mathrm{T}_{3}$ compared to $\mathrm{PR}_{2}$ group $(P<0.05)$. The $\mathrm{DBP}$ in $\mathrm{ER}_{1}$ and $\mathrm{ERD}_{1}$ group were higher at $\mathrm{T}_{1}$ compared to $\mathrm{PR}_{1}$ group $(P<0.05)$. The Serum cortisol concentration were higher at $\mathrm{t}_{1} \sim{ }_{2}$ in $\mathrm{ERD}_{1}$ group compared to $\mathrm{ER}_{1}$ group $(P<0.05)$. The Serum cortisol concentration were higher at $\mathrm{t}_{1} \sim_{3}$ in $\mathrm{ERD}_{2}$ group compared to $\mathrm{ER}_{2}$ group $(P<0.05)$. The Serum ACTH concentration were lower at $\mathrm{t}_{1} \sim_{2}$ in $\mathrm{ERD}_{1}$ group compared to $\mathrm{ER}_{1}$ group $(P<0.05)$. The Serum ACTH concentration were lower at $\mathrm{t}_{1} \sim_{3}$ in $\mathrm{ERD}_{2}$ group compared to $\mathrm{ER}_{2}$ group $(P<0.05)$.

\section{Conclusion}


The administration of dexmedetomidine combined with etomidate can attenuate the inhibition of etomidate on adrenocortical function in elderly patients and maintain intraoperative hemodynamic stability.

\section{Introduction}

Etomidate is a short acting intravenous general anaesthetic derived from imidazole, which shows better sedative effect and no analgesic effect. The drug has been advocated to be used in anesthesia of the elderly and the critically ill patients due to its faint effect on cardiovascular system. The adrenocortical function of the patients anaesthetized with etomidate was suppressed, and it was dose-dependent [1, 2]. Dexmedetomidine is a highly effective and selective a 2-adrenergic receptor agonist, which manifests the effects of sedation, analgesia, anti anxiety and sympathetic inhibition in a dose-dependent manner, with few side effects. At present, clinical research shows that dexmedetomidine can reduce the dose requirements for intravenous or inhalation anesthetics and opioids, and the hemodynamics is more stable during the operation $[3,4,5]$. However, there is no report on the effect of etomidate combined with dexmedetomidine on adrenocortical function in elderly patients. We hypothesized that dexmedetomidine could reduce the dose requirements for etomidate, and the inhibition of adrenocortical function is also attenuated as the dose of etomidate decreased. Therefore, this study was to observe the effect of etomidate combined with dexmedetomidine on adrenocortical function in elderly patients.

\section{Methods}

This study received approval from the Ethics Committee of the affiliated hospital of north sichuan medical college, Sichuan, China (Ref. 2018ER(R)008) in March 2018 and was registered at the Chinese Clinical Trial Registry (http://www.chictr.org.cn/; Registration number: ChiCTR1800015421, 29/03/2018). All participants provided written informed consent before participation. Patients scheduled for elective ureteroscopic holmium laser lithotripsy were enrolled. The inclusion criteria were aged $60-75$ years, American Society of Anaesthesiologists physical status 1 or 2, a diagnosis of kidney or ureteral calculi. The exclusion criteria were as follows: severe functional liver or kidney disease, Cognitive dysfunction, abnormal state of consciousness, with a medical history of steroid therapy, with an endocrine disease.

All patients enrolled were randomly divided into three groups, using sealed envelopes indicating the allocation, to receive intravenous anesthesia with propofol-remifentanil (PR group, $n=60$ ), etomidateremifentanil (ER group, $n=60$ ) and etomidate-remifentanil combined with dexmedetomidine (ERD group, $n=60$ ). Randomization was performed by an anesthesiologist who was not responsible for surgical anesthesia of the patients or data collection. The anaesthesia nurses prepared the dexmedetomidine or saline according to the concealed envelope for random allocation. Patients in each group whose operation time was less than or equal to $1 \mathrm{~h}$ were incorporated into short time operation group $\left(\mathrm{PR}_{1}\right.$ group, $E R_{1}$ group and $E R D_{1}$ group), and whose operation time was more than $1 \mathrm{~h}$ were incorporated into long time operation group ( $\mathrm{PR}_{2}$ group, $\mathrm{ER}_{2}$ group and $\mathrm{ERD}_{2}$ group). The participating patients, surgeons, nurses and anaesthetists were blinded to the treatment allocation. 
Patients were routine monitored with electrocardiography, noninvasive blood pressure(systolic blood pressure, mean arterial pressure and diastolic blood pressure), heart rate, respiratory rate, pulse oximetry, end-tidal CO2, the bispectral index and temperature upon arrival at the operating room. The $6 \mathrm{~L} / \mathrm{min}$ oxygen was provided to all patients by a facemask. After a good upper extremity IV access secured, Anaesthesia was induced with intravenous injection of midazolam $0.04 \mathrm{mg} / \mathrm{Kg}$, propofol $1.5 \mathrm{mg} / \mathrm{Kg}$, remifentanil $2 \mu \mathrm{g} / \mathrm{Kg}$, cis-atracurium $0.2 \mathrm{mg} / \mathrm{Kg}$ in PR group, and midazolam $0.04 \mathrm{mg} / \mathrm{Kg}$, etomidate 0.3 $\mathrm{mg} / \mathrm{Kg}$, remifentanil $2 \mu \mathrm{g} / \mathrm{Kg}$, cis-atracurium $0.2 \mathrm{mg} / \mathrm{Kg}$ in ER group and ERD group. Controlled mechanical ventilation were adjusted to maintain an end-tidal carbon dioxide concentration of 35 to 45 $\mathrm{mmHg}$ after endotracheal tube insertion. Anaesthesia was maintained with propofol plasma target concentration of 2 to $3 \mu \mathrm{g} / \mathrm{ml}$ and remifentanil plasma target concentration of 4 to $6 \mathrm{ng} / \mathrm{ml}$ in PR group, and etomidate plasma target concentration of 4 to $6 \mu \mathrm{g} / \mathrm{ml}$ and remifentanil plasma target concentration of 4 to $6 \mathrm{ng} / \mathrm{ml}$ in ER group and ERD group. Dexmedetomidine $0.4 \mu \mathrm{g} / \mathrm{kg} \cdot \mathrm{h}$ was administrated immediately after induction of anesthesia in ERD group, and equal volume of normal saline was administrated in the other two groups. Cis-atracurium was administered according to intraoperative requirements in all groups. Atracurium and dexmedetomidine were stopped 45 minutes and 20 minutes before the end of the operation, respectively. Propofol, etomidate and remifentanil were stopped five minutes before the end of the operation. The patients were extubated after spontaneous respiration (tidal volume $>6 \mathrm{ml} / \mathrm{kg}$, respiratory rate $>13 / \mathrm{min}$ ), $\mathrm{SpO}_{2}>90 \%$ under air inspiration, $\mathrm{BIS}>80$, and a train-of-four (TOF) ratio $\geq 0.9$. Patients were transferred to the post-anesthesia care unit (PACU) after extubation, and When the modified Aldrete score $>9$, the patients were transferred to the surgical ward. Hypotension (defined as systolic falling more than $20 \%$ before anesthesia or systolic values lower than $80 \mathrm{mmHg}$ ) was treated with ephedrine $6 \mathrm{mg}$ intravenous bolus immediately. Bradycardia (defined as heart $<55$ beats/minute) was treated with $0.3 \mathrm{mg}$ of injection atropine.

The values of SBP, DBP, HR and $\mathrm{SpO}_{2}$ were recorded 5 minutes before anesthesia induction $\left(\mathrm{T}_{0}\right), 5$ minutes after anesthesia induction $\left(T_{1}\right)$, at the beginning of operation $\left(T_{2}\right)$, during operation $\left(T_{3}\right), 6$ hours after operation $\left(T_{4}\right), 12$ hours after operation $\left(T_{5}\right), 24$ hours after operation $\left(T_{6}\right)$ and 48 hours after operation $\left(\mathrm{T}_{7}\right)$.The time of operation, the dosage of etomidate and remifentanil administrated during surgery, the time to spontaneous respiration, recovery and extubation (time from stopping administration of propofol or etomidate to spontaneous respiration, recovery and extubation respectively), and the duration of stay in the PACU were recorded. $6 \mathrm{ml}$ venous blood of the patients was taken before anesthesia induction $\left(\mathrm{t}_{0}\right), 6 \mathrm{~h}\left(\mathrm{t}_{1}\right), 12 \mathrm{~h}\left(\mathrm{t}_{2}\right), 24 \mathrm{~h}\left(\mathrm{t}_{3}\right), 48 \mathrm{~h}\left(\mathrm{t}_{4}\right)$ and $72 \mathrm{~h}\left(\mathrm{t}_{5}\right)$ after anesthesia respectively, All the blood samples were centrifugated at $3000 \mathrm{r} / \mathrm{min}$ for $5 \mathrm{~min}, 2 \mathrm{ml}$ of serum of each sample was taken and stored at $-80^{\circ} \mathrm{C}$ in refrigerator for detection later. The serum cortisol concentration was measured by electrochemiluminescence $(\mathrm{ECL})[6]$, and plasma adrenocorticotropic hormone (ACTH) was determined by radioimmunoassay [7].

\section{Statistical analysis}


Statistical analyses were carried out using SPSS 19.0. Previous study found that 24 hours after administration of etomidate, the plasma cortisol concentration of patients decreased about $4 \mathrm{ug} / \mathrm{ml}[8]$. In order to detect a difference of at least $2 \mathrm{ug} / \mathrm{ml}$ in serum cortisol concentration between the two study groups with $90 \%$ power and $5 \%$ probability of type 1 error, this calculation assumed an SD of 3 in the serum cortisol concentration, 26 subjects were required per group. To account for a $10 \%$ dropout rate, 30 elderly patients in each group were recruited. Quantitative variables were expressed as mean \pm standard deviation(SD), enumeration data was presented as frequencies. Comparison of the demographic data and clinical characteristics of the six groups were made using the Student's t-test, Mann-Whitney U test and $x^{2}$ test as appropriate. Repeated measures analysis of variance was used for comparisons of SBP, DBP, HR, serum cortisol and ACTH concentration levels among groups at each timepoint, if comparison between groups was positive, the SNK poet hoc test was performed. The statistical significance was determined as $p<0.05$.

\section{Results}

One hundred and eighty patients were screened for eligibility, and subsequently allocated to three groups. No patient dropped out of the trial. A total of one hundred and eighty patients completed the study (shown in Fig. 1).

There were no differences in age, weight, ASA grade and sex ratio among patients in each group (shown in table 1.1 and table 1.2).

The duration of surgery and the length of stay in the PACU were similar among the three short time operation groups. There was no difference in remifentanil dosage between the $\mathrm{ER}_{1}$ group and $\mathrm{ERD}_{1}$ group.The dosage of etomidate was significantly lower in $\mathrm{ERD}_{1}$ group compared with $\mathrm{ER}_{1}$ group $(P<$ 0.05). The time to spontaneous respiration, tracheal extubation time and the time to recovery were longer in group $E D_{1}$ compared with group $\operatorname{ER}_{1}(P<0.05)$, (shown in table 2.1). The duration of surgery were similar among the three long time operation groups. The dosage of remifentanil and etomidate were significantly lower in $\mathrm{ERD}_{2}$ group compared with $\mathrm{ER}_{2}$ group $\square \mathrm{P}<0.05 \rrbracket$. The time to spontaneous respiration, tracheal extubationtime, the time to recovery and the PACU stay time were delayed greater in group ERD ${ }_{2}$ compared with group ER2 $(P<0.05)$, (shown in table2.2).

The SBP were lower at $T_{1}$ compared to $T_{0}$ in all short time operation groups $(P<0.05)$. The SBP in $E R_{1}$ and $E R D_{1}$ group were higher at $T_{1}$ and $T_{3}$ compared to $P R_{1}$ group $(P<0.05)$. The $S B P$ in $E R D_{1}$ group were lower at $T_{4}$ compared to ER1 group $(P<0.05)$, (shown in table 3.1). The SBP were lower at $T 1$ compared to T0 in three long time operation groups $(P<0.05)$. The SBP in ER2 and ERD2 group were higher at T1 and T3 compared to PR2 group $(P<0.05)$. The SBP in ERD2 group were lower at T4 compared to ER2 group $(P<0.05)$, (shown in table 3.2$)$.

The DBP were lower at T1compared to T0 in three short time operation groups $(P<0.05)$. The DBP in ER1 and ERD1 group were higher at T1 compared to PR1 group $(\mathrm{P}<0.05)$. The DBP in ERD1 group were lower 
at T4 compared to ER1 group $(\mathrm{P}<0.05)$, (shown in table 4.1). The DBP were lower at T1compared to T0 in all long time operation groups $(P<0.05)$. The DBP in ER1 and ERD1 group were higher at T1compared to PR1 group $(P<0.05)$. The DBP in ERD1 group were lower at T4 compared to ER1 group $(P<0.05)$, (shown in table 4.2).

The HR were lower at T1and higher at T4compared to $\mathrm{T}_{0}$ in three short time operation groups $(P<0.05)$. The HR in ERD $D_{1}$ group were lower at $\mathrm{T}_{3}$ and $\mathrm{T}_{4}$ compared to $\mathrm{PR}_{1}$ group and $\mathrm{ER}_{1}$ group $(P<0.05)$, shown in (shown in table 5.1). The HR were lower at $T_{1}$ compared to $T_{0}$ in three long time operation groups $(P<$ 0.05). The HR were higher at $T_{4}$ compared to $T_{0}$ in $P R_{2}$ group and $E R_{2}$ group, and lower at $T_{4}$ compared to $\mathrm{T}_{0}$ in $\mathrm{ERD}_{2}$ group $(P<0.05)$. The HR in $\mathrm{ERD}_{2}$ group were lower at $\mathrm{T}_{3}$ and $\mathrm{T}_{4}$ compared to $\mathrm{PR}_{2}$ group and $\mathrm{ER}_{2}$ group $(P<0.05)$, (shown in table 5.2).

The Serum cortisol concentration were lower at $t_{1 \sim 2}$ in $E R_{1}$ group and $t_{1}$ in $E R D_{1}$ group compared to $t_{0}$ and $\mathrm{PR}_{1}$ group $(P<0.05)$. The Serum cortisol concentration were higher at $\mathrm{t}_{1} \sim_{2}$ in $\mathrm{ERD}_{1}$ group compared to $\mathrm{ER}_{1}$ group $(P<0.05)$, (shown in table 6.1). The Serum cortisol concentration were lower at $\mathrm{t}_{1 \sim 3}$ in $\mathrm{ER}_{2}$ group and $\mathrm{t}_{1 \sim 2}$ in $\mathrm{ERD}_{2}$ group compared to $\mathrm{t}_{0}$ and $\mathrm{PR}_{2}$ group $(P<0.05)$. The Serum cortisol concentration were higher at $\mathrm{t}_{1} \sim_{3}$ in $\mathrm{ERD}_{2}$ group compared to $\mathrm{ER}_{2}$ group $(P<0.05)$, (shown in table 6.2).

The Serum ACTH concentration were higher at $t_{1 \sim 2}$ in $E R_{1}$ group and $t_{1}$ in $E R D_{1}$ group compared to $t_{0}$ and $\mathrm{PR}_{1}$ group $(P<0.05)$. The Serum ACTH concentration were lower at $\mathrm{t}_{1} \sim_{2}$ in $\mathrm{ERD}_{1}$ group compared to $\mathrm{ER}_{1}$ group $(P<0.05)$, (shown in table 7.1). The Serum ACTH concentration were higher at $\mathrm{t}_{1 \sim 3}$ in $\mathrm{ER}_{2}$ group and $t_{1 \sim 2}$ in $\mathrm{ERD}_{2}$ group compared to $\mathrm{t}_{0}$ and $\mathrm{PR}_{2}$ group $(P<0.05)$. The Serum ACTH concentration were lower at $\mathrm{t}_{1} \sim{ }_{3}$ in $\mathrm{ERD}_{2}$ group compared to $\mathrm{ER}_{2}$ group $(P<0.05)$, (shown in table 7.2).

\section{Discussion}

In this study, we found that the blood pressure during both induction of anaesthesia and surgery was more stable when anesthetized with etomidate than propofol, indicating that the elderly patients performed good hemodynamic stability when anesthetized with etomidate. After intravenous administration of etomidate, the plasma concentration levels of cortisol and ACTH returned to preoperative levels $24 \mathrm{~h}$ and $48 \mathrm{~h}$ after operation in short time operation group and long time operation group, respectively. However, after administration of dexmedetomidine $0.4 \mu \mathrm{g} / \mathrm{kg} . \mathrm{h}$, the serum cortisol and ACTH concentrations returned to the preoperative level 12 hours after operation in short time operation group, and 24 hours after operation in long time operation group. The spontaneous respiration recovery and anesthesia revival were slightly delayed after administration of dexmedetomidine.

In clinic, the induction of anesthesia with propofol often leads to the decrease of arterial blood pressure [9]. Due to the degradation of organ function and the declination of physiological function, it is easier to induce hypotension in elderly patients anesthetized with propofol [10]. The blood pressure was decreased significantly compared to the baseline in patients by using propofol and etomidate for anesthesia 
induction, and the decrease was greater in the propofol group compared to etomidate group [11]. In this study, $5 \mathrm{~min}$ after induction of anesthesia with propofol, the systolic pressure, diastolic pressure and heart rate decreased by $23.5 \%, 28.4 \%$ and $13 \%$ respectively. This is mainly attributed to propofol reduces cardiac output and systemic vascular resistance, and inhibits baroreceptor reflex [10]. However, in the etomidate group, systolic blood pressure decreased by $14.6 \%$, diastolic blood pressure decreased by $12 \%$ and heart rate decreased by $14 \% 5 \mathrm{~min}$ after induction of anesthesia. Although there was no difference in the decrease of heart rate, the decrease of systolic and diastolic blood pressure was more gently in etomidate group compared to propofol group. Meanwhile, the blood pressure of patients during surgery was significantly lower in propofol group compared to etomidate group. It is suggested that the hemodynamic stability in the elderly patients can be better maintained with etomidate anesthesia.

Although etomidate provides rapid onset, rapid recovery and reliable cardiovascular stability [12], the suppressive effects of etomidate on adrenocortical function limits its clinical application by anesthetists, especially the increased mortality in critically ill patients was potentially due to the adrenal suppressive effects of etomidate [13]. A specific and reversible blockade of the 11a-hydroxylation and 11 $\beta$ hydroxylation of adrenal steroid synthesis caused by etomidate lead to the decrease of cortisol, corticosterone, and aldosterone synthesis [14]. It was found that the serum corticosterone concentration decreased significantly and lasted for more than 3 hours after 120 minutes of etomidate infusion in rats [14]. Clinical studies found that when intravenous infusion of etomidate was used for anesthesia induction, the levels of plasma cortisol were suppressed in the first $6 \mathrm{~h}$ after induction by intravenous infusion of etomidate, and returned to pre anesthesia levels 24 hours later [15]. The serum cortisol concentration of patients anesthetized with etomidate for electroconvulsive therapy for several times decreased significantly at $24 \mathrm{~h}$ after each anesthesia, and returned to the preoperative level $48 \mathrm{~h}$ after anesthesia [16]. These studies suggested that the suppression of etomidate on adrenal cortical function was dose-dependent In this study, etomidate $0.3 \mathrm{mg} / \mathrm{kg}$ was used for anesthesia induction, and the anesthesia was maintained with intravenous target concentration of etomidate 4 to $6 \mu \mathrm{g} / \mathrm{ml}$. In the short time operation group, the serum cortisol level was significantly lower compared to preoperative level at 6 to $12 \mathrm{~h}$ after operation, and there was no significant difference in serum cortisol level between the baseline and $24 \mathrm{~h}$ after operation. The plasma cortisol concentration was decreased more significantly at 6 to $24 \mathrm{~h}$ after operation, and returned to the preoperative level at $48 \mathrm{~h}$ after operation in the long time operation group. The results showed that the adrenocortical function of the elderly patients anesthetized with etomidate was suppressed, and the suppression was also prolonged with the increase of anesthesia time.

Dexmedetomidine is a highly specific a2-adrenoreceptor agonist with short half-life period (about 2 hours). It has a dose-dependent sedative and analgesic effect, and has no adverse effect on respiration [17]. The application of dexmedetomidine $(0.5 \mathrm{~g} \cdot \mathrm{kg}-1)$ in pediatric patients anesthetized with sevoflurane can decrease the heart rate of children, but there is no significant change in SBP, DBP or PECO2 [4]. It is shown that dexmedetomidine as an adjunct for inhalation anesthetics can effectively maintain the stability of circulation and respiration during operation. In recent clinical trials, the effect of dexmedetomidine on the requirement for propofol and remifentanil in total intravenous anesthesia was 
studied. It was found that the administration of dexmedetomidine significantly decreased both the requirements for propofol and remifentanil during anesthesia induction and the dosage of propofol administrated during surgery. The administration of dexmedetomidine also delayed the requirement for postoperative analgesia $[3,18]$. In this study, when dexmedetomidine was added to intravenous anesthesia with etomidate, the intraoperative dosages of etomidate were reduced by $17 \%$ and $22 \%$ in the short time operation group and long time operation group respectively, and the dosage of remifentanil was reduced by $13 \%$ in long time operation group. It was consistent with the above research results.

In this study, the administration of dexmedetomidine not only reduced the etomidate requirements for total intravenous anesthesia in elderly patients, but also attenuated and shortened the inhibitory effect of etomidate on adrenocortical function in elderly patients. This is mainly because the inhibition effects of etomidate on adrenal cortex function were dose-dependent [19], the administration of dexmedetomidine significantly reduced the requirement for etomidate, and with the reduction of etomidate dose, the inhibitory effect of etomidate on adrenal cortex was correspondingly attenuated in this study. In vitro studies showed that dexmedetomidine combined with etomidate had a stronger inhibitory effect on human adrenocortical cells than etomidate alone [20]. However, some scholars studied the effect of dexmedetomidine and etomidate on adrenocortical function in children and found that $3 \mathrm{~h}$ after induction of anesthesia, the serum cortisol concentration of patients in the etomidate group was the lowest, while there was no difference between dexmedetomidine group and the control group, indicating that dexmedetomidine had little or no effect on adrenocortical function [21]. The researches above showed that the inhibitory effect of dexmedetomidine on adrenal function is controversial currently. The inhibitory effect of dexmedetomidine on adrenocortical function in elderly patients was not studied in our study, so the effect of dexmedetomidine on adrenocortical function in elderly patients is still unknown.

There are limitations in this study. Firstly, we didn't design a trial to identify the effect of dexmedetomidine alone on adrenocortical function in elderly patients, it is not clear whether the administration of dexmedetomidine suppress the adrenocortical function. Secondly, an enzymatic block of 11-b-hydroxylase was demonstrated in a patient who received a prolonged infusion of etomidate [21]. We didn't observe the enzymatic block of 11-b-hydroxylase both in short and long time operation groups in this study, and the effects of intravenous infusion of dexmedetomidine combined with etomidate on the enzymatic block of 11-b-hydroxylase at different times need to be further studied. Thirdly, the principal adrenocortical products are cortisol, aldosterone and dehydroepiandrosterone sulphate [22]. In our study, we only observed changes in plasma concentrations of cortisol and adrenocorticotropin, but the effect of administration of etomidate combined with dexmedetomidine on adrenocortical secretion of aldosterone was not clear. Fourthly, in our study, the operation time of ureteral holmium laser lithotripsy was within 2.5h, and the effect of etomidate combined with dexmedetomidine infusion for more than $2.5 \mathrm{~h}$ on adrenocortical function was unclear.

In conclusion, the inhibitory effect of etomidate on adrenocortical function in elderly patients was prolonged with the duration of intravenous anesthesia with etomidate. The administration of 
dexmedetomidine combined with etomidate can attenuate the inhibition of etomidate on adrenocortical function in elderly patients and maintain intraoperative hemodynamic stability.

\section{Declarations}

\section{ACKNOWLEDGMENTS}

The authors thank the participants for their enthusiastic collaboration, the urological surgeons and nurses assisted in specimen collection, and the laboratory physician helped to test for plasma cortisol and $\mathrm{ACTH}$.

\section{Author contributions}

FJ.W. wrote the manuscript. FJ.W and SS.Z. analysed and interpreted the data. LY.G. performed clinical data acquisition. FJ.W. and JB.L. designed and supervised the origin PopCol study, JB.L. and N.W. processed all the samples and detected the Plasma concentration of ACTH and cortisol. All authors contributed to discuss the results and to research directions. All authors approved the manuscript.

\section{FUNDING}

This study was funded, in part, by the foundation of Sichuan Medical Association (EH-MN14-06). None of the funding sources played a role in the design, collection, analysis, or interpretation of the data or in the decision to submit the manuscript for publication.

\section{STATEMENT OF ETHICS}

All procedures performed in studies involving human participants were in accordance with the ethical standards of the institutional and/or national research committee and with the 1964 Helsinki declaration and its later amendments or comparable ethical standards. Following the approval by the Ethics Committee of the affiliated hospital of north sichuan medical college(Ref. 2018ER(R)008), we obtained the written informed consent from all the participants for this randomized prospective clinical trial conducted at the affiliated hospital of north sichuan medical college, on patients with kidney or ureteral calculi.

\section{CONFLICT OF INTEREST}

None of the authors have any potential conflicts of interest relevant to this article.

\section{References}

1. Sunshine, J. E. et al. Etomidate, adrenal function, and mortality in critically ill patients. Respir. Care, 58 (4), 639-646 https://doi.org/10.4187/respcare.01956 (2013). 
2. Mozański, M., Tomaszewski, D., Rybicki, Z., Bejm, J. \& Balkota, M. Etomidate, but not thiopental, decreases serum cortisol concentration in morbidly obese patients. A randomized controlled trial. Anaesthesiol. Intensive Ther, 48 (1), 7-12 https://doi.org/10.5603/ait.2016.0002 (2016).

3. Dutta, A. et al. The Effect of Dexmedetomidine on Propofol Requirements During Anesthesia Administered by Bispectral Index-Guided Closed-Loop Anesthesia Delivery System: A Randomized Controlled Study. Anesthesia and Analgesia, 129 (1), 84-91 (2019). 10.1213/ane. 0000000000003470

4. Deutsch, E. \& Tobias, J. D. Hemodynamic and respiratory changes following dexmedetomidine administration during general anesthesia: sevoflurane vs desflurane. Paediatr Anaesth, 17 (5), 438444 https://doi.org/10.1111/j.1460-9592 (2007).

5. Mousa, S. A. \& Alsobky, H. A. E. Efficacy and effect of TIVA with propofol or dexmedetomidine versus sevoflurane without muscle relaxant during repair of the brachial plexus. Egyptian Journal of Anaesthesia, 29, 31-40 (2013). 10.1016 /j.egja.2012.08.001

6. Możański, M., Tomaszewski, D., Rybicki, Z., Bejm, J. \& Bałkota, M. Etomidate, but not thiopental, decreases serum cortisol concentration in morbidly obese patients. A randomized controlled trial. Anaesthesiol Intensive Ther, 48 (1), 7-12 https://doi.org/10.5603/ait.2016.0002 (2016).

7. Allolio, B. et al. Nonhypnotic low-dose etomidate for rapid correction of hypercortisolaemia in Cushing's syndrome. Klin Wochenschr, 66 (8), 361-364 https://doi.org/10.1007/bf01735795 (1988).

8. Hino, H. et al. Comparison between hemodynamic effects of propofol and thiopental during general anesthesia induction with remifentanil infusion: a double-blind, age-stratified, randomized study. $J$ anesth, 33, 509-515 https://doi.org/10.1007/s00540-019-02657-x (2019).

9. Hu, B., Zhong, Y. \& Zou, X. Propofol vs. thiopental in hypotention after GA induction. J Anesth, 33 (6), 705 https://doi.org/10.1007/s00540-019-02686-6 (2019).

10. Chiu, C. L., Tew, G. P. \& Wang, C. Y. The effect of prophylactic metaraminol on systemic hypotension caused by induction of anaesthesia with propofol in patients over 55 years old. Anaesthesia, 56 (9), 893-897 https://doi.org/10.1046/j.1365-2044.2001 (2001).

11. Yağan, Ã., Taş, N., Küçük, A., Hancı, V. \& Yurtlu, B. S. Haemodynamic Responses to Tracheal Intubation Using Propofol, Etomidate and Etomidate-Propofol Combination in Anaesthesia Induction. J Cardiovasc Transl, 7 (4), 134-140 https://doi.org/10.15171/jcvtr.2015.30 (2015).

12. Możański, M., Tomaszewski, D., Rybicki, Z., Bejm, J. \& Bałkota, M. Etomidate, but not thiopental, decreases serum cortisol concentration in morbidly obese patients. A randomized controlled trial. Anaesthesiol Intensive Ther, 48 (1), 7-12 https://doi.org/10.5603/ait.2016.0002 (2016).

13. Fengler, B. T. Should etomidate be used for rapid-sequence intubation induction in critically ill septic patients? Am J Emerg Med, 26 (2), 229-232 (2008). 10.1016/ j.ajem.2008.04.009

14. Ge, R., Pejo, E., Cotten, J. F. \& Raines, D. E. Adrenocortical suppression and recovery after continuous hypnotic infusion: etomidate versus its soft analogue cyclopropyl-methoxycarbonyl metomidate. Crit Care, 17 (1), R20 https://doi.org/10.1186/cc12494 (2013). 
15. Prakash, M. V. S. S., Gnanasekar, R., Sakthirajan, P. \& Adole, P. S. A comparative study of two infusion doses of etomidate for induction vs standard induction dose of etomidate. Eur J Clin pharmacol, 75 (7), 889-894 https://doi.org/10.1007/s00228-019-02681-6 (2019).

16. Wang, N., Wang, X. H., Lu, J. \& Zhang, J. Y. The effect of repeated etomidate anesthesia on adrenocortical function during a course of electroconvulsive therapy. J ECT, 27 (4), 281-285 https://doi.org/10.1097/yct.0b013e3182182be0 (2011).

17. Poorzamany Nejat Kermany, M., Dahi, M., Yamini Sharif, R. \& Radpay, B. Comparison of the Effects of Dexmedetomidine and Remifentanil on Cognition State After Cataract Surgery. Anesth Pain Med, 6 (3), e33448 https://doi.org/10.5812/aapm.33448 (2016).

18. Le Guen, M. et al. Dexmedetomidine reduces propofol and remifentanil requirements during bispectral index-guided closed-loop anesthesia: a double-blind, placebo-controlled trial. Anesth Analg, 118 (5), 946-955 https://doi.org/10.1213/ane.0000000000000185 (2014).

19. Malapero, R. J., Zaccagnino, M. P., Brovman, E. Y., Kaye, A. D. \& Urman, R. D. Etomidate derivatives: Novel pharmaceutical agents in anesthesia. J Anaesthesiol Clin Pharmacol, 33 (4), 429-431 https://doi.org/10.4103/0970-9185.222521 (2017).

20. Gu, H., Zhang, M., Cai, M. \& Liu, J. Combined Use of Etomidate and Dexmedetomidine Produces an Additive Effect in Inhibiting the Secretion of Human Adrenocortical Hormones. Med Sci Monit, 21, 3528-3535 Doi: 10.12659/MSM. 894728 (2015).

21. Wagner, R. L. \& White, P. F. Etomidate inhibits adrenocortical function in surgical patients., 61 (6), 647-651 https://doi.org/10.1097/00000542-198412000-00003 (1984).

22. Sharp, A. M., Handelsman, D. J., Ristuccia, R. M. \& Turtle, J. R. Dexamethasone suppression of adrenocortical function. Clin Chem, 28 (6), 1333-1334 (1982). 10.1093/clinchem/28.6.1333

\section{Tables}

The Patient characteristics in short operation time groups are shown in table 1.1. Patient characteristics were similar among the three groups, (Table 1.1).

Table 1.1 Demographic data in short operation time groups.

\begin{tabular}{|llllll|}
\hline Patient characteristics & $\mathrm{PR}_{1}$ & $\mathrm{ER}_{1}$ & $\mathrm{ERD}_{1}$ & $F / X^{2}$ values & $P$ values \\
& $n=28$ & $n=29$ & $n=32$ & & \\
\hline Sex囚male /female $\mathbb{1}$ & $15 / 13$ & $14 / 15$ & $16 / 16$ & 0.0691 & 0.7926 \\
\hline Age $(\mathrm{y})$ & $66.4 \pm 4.6$ & $65.6 \pm 3.1$ & $67.3 \pm 4.8$ & 1.21 & 0.3047 \\
\hline Weight $(\mathrm{kg})$ & $57.5 \pm 5.8$ & $56.9 \pm 7.1$ & $58.0 \pm 6.4$ & 1.03 & 0.3612 \\
\hline $\mathrm{ASA}(\mathrm{I} / \mathrm{II})$ & $9 / 19$ & $11 / 18$ & $13 / 19$ & 0.4488 & 0.5029 \\
\hline
\end{tabular}


Values are mean $\pm S D$. ASA: American Society of Anesthesiologists; $\mathrm{PR}_{1}$ : Propofol-remifentanil; $\mathrm{ER}_{1}$ : Etomidate-remifentanil; $\mathrm{ERD}_{1}$ : Etomidate-remifentanil and dexmedetomidine

The Patient characteristics in long operation time groups are shown in table 1.2. Patient characteristics were similar among the three groups, (Table 1.2).

Table 1.2 Demographic data in long operation time groups.

\begin{tabular}{|llllll|}
\hline Patient characteristics & $\mathrm{PR}_{2}$ & $\mathrm{ER}_{2}$ & $\mathrm{ERD}_{2}$ & $F / X^{2}$ values & $P$ values \\
& $n=32$ & $n=31$ & $n=28$ & & \\
\hline Sex囚male /female $\mathbb{}$ & $15 / 17$ & $15 / 16$ & $15 / 13$ & 0.2588 & 0.611 \\
Age $(\mathrm{y})$ & $65.7 \pm 4.0$ & $65.2 \pm 3.5$ & $66.1 \pm 3.8$ & 0.51 & 0.6039 \\
Weight $(\mathrm{kg})$ & $56.9 \pm 7.0$ & $56.6 \pm 8.8$ & $58.7 \pm 9.0$ & 0.52 & 0.5967 \\
ASA(I/II) & $14 / 18$ & $12 / 19$ & $11 / 17$ & 0.1293 & 0.7192 \\
\hline
\end{tabular}

Values are mean $\pm S D$. ASA: American Society of Anesthesiologists; $\mathrm{PR}_{2}$ : Propofol-remifentanil; $\mathrm{ER}_{2}$ : Etomidate-remifentanil; $\mathrm{ERD}_{2}$ : Etomidate-remifentanil and dexmedetomidine

The clinical characteristics in short operation time groups are shown in table2.1.The duration of surgery and the length of stay in the PACU were similar among the three groups. There was no difference in remifentanil dosage between the $E R_{1}$ group and $E R D_{1}$ group. The dosage of etomidate was significantly lower in $\mathrm{ERD}_{1}$ group compared with $\mathrm{ER}_{1}$ group $\mathbb{P} P<0.05 \rrbracket$. The time to spontaneous respiration, tracheal extubation time and the time to recovery were significantly delayed in group $\mathrm{ERD}_{1}$ compared with group $\mathrm{ER}_{1}(P<0.05)$, (table 2.1).

Table 2.1 Clinical characteristics in short operation time groups 


\begin{tabular}{|c|c|c|c|c|c|}
\hline Clinical characteristics & $\begin{array}{l}\mathrm{PR}_{1} \\
n=28\end{array}$ & $\begin{array}{l}\mathrm{ER}_{1} \\
n=29\end{array}$ & $\begin{array}{l}\mathrm{ERD}_{1} \\
n=32\end{array}$ & $\begin{array}{l}F \\
\text { values }\end{array}$ & $\begin{array}{l}P \\
\text { values }\end{array}$ \\
\hline duration of surgery $₫$ minute $\rrbracket$ & $45.9 \pm 7.1$ & $46.6 \pm 5.9$ & $47.3 \pm 6.1$ & 0.11 & 0.8978 \\
\hline 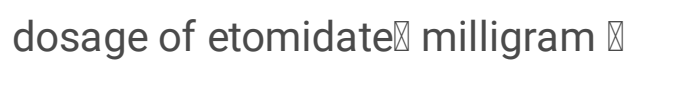 & - & $54.2 \pm 5.9$ & $45.1 \pm 5.6^{\$}$ & 36.4 & 0.000 \\
\hline dosage of remifentanil『microgram $\rrbracket$ & - & $915.7 \pm 41.2$ & $897.9 \pm 38.0$ & 2.95 & 0.0911 \\
\hline $\begin{array}{l}\text { time to spontaneous } \\
\text { respiration (minute) }\end{array}$ & $16.5 \pm 1.7$ & $17.2 \pm 2.4$ & $19.1 \pm 2.5^{\# \$}$ & 10.84 & 0.000 \\
\hline time to recovery (minute) & $18.9 \pm 2.1$ & $19.7 \pm 2.7$ & $23.4 \pm 2.6^{\# \star \$}$ & 30.24 & 0.000 \\
\hline tracheal extubation time (minute) & $20.6 \pm 2.4$ & $21.5 \pm 2.9$ & $26.4 \pm 2.5^{\# \star \$}$ & 44.48 & 0.000 \\
\hline PACU stay time(minute) & $59.9 \pm 6.2$ & $58.4 \pm 5.4$ & $62.1 \pm 9.4$ & 1.93 & 0.1511 \\
\hline
\end{tabular}

Values are mean $\pm S D$. PR: Propofol-remifentanil; ER: Etomidate-remifentanil; ERD: Etomidate-remifentanil and dexmedetomidine; PACU: postanesthesia care unit. ${ }^{*} p<0.05$ vs. $\mathrm{PR}_{1}$ group; $\$ p<0.05$ vs. $\mathrm{ER}_{1}$ group

The clinical characteristics in long operation time groups are shown in table2.2.The duration of surgery were similar among the three groups. The dosage of remifentanil and etomidate were significantly lower in $\mathrm{ERD}_{2}$ group compared with $\mathrm{ER}_{2}$ group $\triangle P<0.05 \rrbracket$. The time to spontaneous respiration, tracheal extubation time, the time to recovery and the PACU stay time were longer in group $\mathrm{ERD}_{2}$ compared with group $\mathrm{ER}_{2}(P<0.05),($ table2.2).

Table 2.2 Clinical characteristics in long operation time groups

\begin{tabular}{|c|c|c|c|c|c|}
\hline Clinical characteristics & $\begin{array}{l}\mathrm{PR}_{2} \\
n=32\end{array}$ & $\begin{array}{l}\mathrm{ER}_{2} \\
n=31\end{array}$ & $\begin{array}{l}\mathrm{ERD}_{2} \\
n=28\end{array}$ & $\begin{array}{l}F \\
\text { values }\end{array}$ & $\begin{array}{l}P \\
\text { values }\end{array}$ \\
\hline duration of surgery $\llbracket$ minute $\rrbracket$ & $105.5 \pm 20.6$ & $102.9 \pm 16.2$ & $104.5 \pm 19.7$ & 0.54 & 0.5831 \\
\hline $\begin{array}{l}\text { dosage of etomidate } \\
\bigotimes \text { milligram } \rrbracket\end{array}$ & - & $95.0 \pm 10.1$ & $74.4 \pm 7.1^{\$}$ & 81.23 & 0.000 \\
\hline $\begin{array}{l}\text { dosage of remifentanil } \\
\text { 『microgram } \rrbracket\end{array}$ & - & $1676.5 \pm 188.6$ & $1452.9 \pm 132.0 * \$$ & 25.55 & 0.000 \\
\hline $\begin{array}{l}\text { time to spontaneous } \\
\text { respiration (minute) }\end{array}$ & $17.4 \pm 2.1$ & $18.1 \pm 2.7$ & $19.9 \pm 2.6^{\# \$}$ & 7.91 & 0.0007 \\
\hline time to recovery (minute) & $19.8 \pm 2.1$ & $20.3 \pm 3.0$ & $25.6 \pm 2.8^{\# \$}$ & 41.61 & 0.000 \\
\hline $\begin{array}{l}\text { tracheal extubation } \\
\text { time (minute) }\end{array}$ & $21.3 \pm 2.1$ & $22.4 \pm 3.2$ & $27.75 \pm 3.4^{\# \$}$ & 38.68 & 0.000 \\
\hline PACU stay time(minute) & $69.4 \pm 7.1$ & $71.7 \pm 9.9$ & $77.7 \pm 11.4^{\# \$}$ & 6.01 & 0.0036 \\
\hline
\end{tabular}


Values are mean $\pm S D$. $\mathrm{PR}_{2}$ : Propofol-remifentanil; $\mathrm{ER}_{2}$ : Etomidate-remifentanil; $\mathrm{ERD}_{2}$ : Etomidateremifentanil and dexmedetomidine; PACU:postanesthesia care unit. ${ }^{\#} p<0.05$ vs. $\mathrm{PR}_{2}$ group; $\$ p<0.05$ vs. $\mathrm{ER}_{2}$ group

The SBP at different time points in short operation time groups are shown in table 3.1. The SBP were lower at $\mathrm{T}_{1}$ compared to $\mathrm{T}_{0}$ in three groups $(P<0.05)$. The SBP in $\mathrm{ER}_{1}$ and $\mathrm{ERD}_{1}$ group were higher at $\mathrm{T}_{1}$ and $\mathrm{T}_{3}$ compared to $\mathrm{PR}_{1}$ group $(P<0.05)$. The SBP in $\mathrm{ERD}_{1}$ group were lower at $\mathrm{T}_{4}$ compared to $\mathrm{ER}_{1}$ groups $(P<0.05)$, (table 3.1).

Table 3.1 The SBP at $T_{0}, T_{1}, T_{2}, T_{3}, T_{4}, T_{5}, T_{6}$ and $T_{7}$ in short operation time groups.

\begin{tabular}{|llllll|}
\hline time & $\mathrm{PR}_{1}$ & $\mathrm{ER}_{1}$ & $\mathrm{ERD}_{1}$ & $F$ values & $P$ values \\
& $n=28$ & $n=29$ & $n=32$ & & \\
$\mathrm{~T}_{0}$ & $122.6 \pm 11.8$ & $123.4 \pm 9.8$ & $121.7 \pm 11.7$ & 0.22 & 0.8005 \\
$\mathrm{~T}_{1}$ & $93.8 \pm 8.4^{\star \$}$ & $105.7 \pm 6.7^{\star \#}$ & $103.0 \pm 9.5^{\star \#}$ & 14.92 & 0.000 \\
$\mathrm{~T}_{2}$ & $115.3 \pm 10.6^{\star}$ & $116.5 \pm 7.4^{\star}$ & $115.0 \pm 8.4^{\star}$ & 0.55 & 0.5818 \\
$\mathrm{~T}_{3}$ & $112.5 \pm 8.0^{\star \$}$ & $118.6 \pm 6.3^{\star \#}$ & $117.6 \pm 9.1^{\star \# \#}$ & 4.93 & 0.0095 \\
$\mathrm{~T}_{4}$ & $129.1 \pm 8.6^{\star}$ & $130.4 \pm 10.0^{\star}$ & $124.0 \pm 7.0^{\# \$}$ & 5.2 & 0.0074 \\
\hline $\mathrm{T}_{5}$ & $120.3 \pm 7.9$ & $123.1 \pm 6.9$ & $121.2 \pm 7.6$ & 0.78 & 0.461 \\
\hline $\mathrm{T}_{6}$ & $119.8 \pm 9.2$ & $122.9 \pm 10.4$ & $121.7 \pm 8.5$ & 0.58 & 0.56 \\
\hline $\mathrm{T}_{7}$ & $121.7 \pm 12.1$ & $124.3 \pm 10.3$ & $122.6 \pm 10.1$ & 0.19 & 0.8285 \\
\hline$F$ values & 119.93 & 60.07 & 50.4 & - & - \\
\hline$P$ values & 0.000 & 0.000 & 0.000 & - & - \\
\hline
\end{tabular}

Values are mean $\pm S D . \mathrm{PR}_{1}$ : Propofol-remifentanil; ER $\mathrm{ER}_{1}$ : Etomidate-remifentanil; ERD 1 : Etomidateremifentanil and dexmedetomidine; $T_{0}$ : before the induction of anesthesia, $T_{1}: 5 \mathrm{~min}$ after induction of anesthesia, $T_{2}$ : the beginning of operation, $T_{3}$ : during operation, $T_{4}: 6 h$ after surgery, $T_{5}: 12 h$ after surgery. $\mathrm{T}_{6}$ : $24 \mathrm{~h}$ after surgery. $\mathrm{T}_{7}: 48 \mathrm{~h}$ after surgery. ${ }^{*} p<0.05$ vs. $\mathrm{T}_{0} ;{ }^{\#} p<0.05$ vs. $\mathrm{PR}_{1}$ group; ${ }^{\$} p<0.05$ vs. $\mathrm{ER}_{1}$ group

The SBP at different time points in long operation time groups are shown in table 3.2. The SBP were lower at $\mathrm{T}_{1}$ compared to $\mathrm{T}_{0}$ in three groups $(P<0.05)$. The SBP in $\mathrm{ER}_{2}$ and $\mathrm{ERD}_{2}$ group were higher at $\mathrm{T}_{1}$ and $\mathrm{T}_{3}$ compared to $\mathrm{PR}_{2}$ group $(P<0.05)$. The SBP in $\mathrm{ERD}_{2}$ group were lower at $\mathrm{T}_{4}$ compared to $\mathrm{ER}_{2}$ groups $(P<0.05)$, (table 3.2$)$. 
Table 3.2 The SBP at $T_{0}, T_{1}, T_{2}, T_{3}, T_{4}, T_{5}, T_{6}$ and $T_{7}$ in long operation time groups.

\begin{tabular}{|llllll|}
\hline time & $\mathrm{PR}_{2}$ & $\mathrm{ER}_{2}$ & $\mathrm{ERD}_{2}$ & $F$ values & $P$ values \\
& $n=32$ & $n=31$ & $n=28$ & & \\
\hline $\mathrm{T}_{0}$ & $122.5 \pm 9.2$ & $121.3 \pm 11.4$ & $120.6 \pm 10.9$ & 0.14 & 0.8705 \\
\hline $\mathrm{T}_{1}$ & $95.3 \pm 6.8^{\star} \$$ & $102.8 \pm 8.0^{\star \#}$ & $104.5 \pm 9.3^{\star \#}$ & 11.54 & 0.000 \\
\hline $\mathrm{T}_{2}$ & $115.1 \pm 7.9^{\star}$ & $118.3 \pm 8.4$ & $116.1 \pm 9.8$ & 1.09 & 0.3416 \\
\hline $\mathrm{T}_{3}$ & $113.5 \pm 8.1^{\star}$ & $120.0 \pm 8.5^{\#}$ & $118.2 \pm 10.1^{\#}$ & 4.77 & 0.0108 \\
\hline $\mathrm{T}_{4}$ & $130.2 \pm 9.8^{\star}$ & $128.2 \pm 10.4^{\star}$ & $122.6 \pm 9.5^{\# \$}$ & 4.31 & 0.0164 \\
\hline $\mathrm{T}_{5}$ & $120.3 \pm 8.0$ & $122.1 \pm 9.1$ & $119.8 \pm 7.4$ & 0.97 & 0.3817 \\
\hline $\mathrm{T}_{6}$ & $123.0 \pm 9.2$ & $122.5 \pm 9.5$ & $118.6 \pm 8.0$ & 2.14 & 0.1237 \\
\hline $\mathrm{T}_{7}$ & $124.0 \pm 8.3$ & $120.1 \pm 10.3$ & $123.2 \pm 9.3$ & 1.11 & 0.3357 \\
\hline$F$ values & 48 & 18.4 & 10.65 & - & - \\
\hline$P$ values & 0.000 & 0.000 & 0.000 & - & - \\
\hline
\end{tabular}

Values are mean $\pm S D$. $\mathrm{PR}_{1}$ : Propofol-remifentanil; $\mathrm{ER}_{1}$ : Etomidate-remifentanil; ERD 1 : Etomidateremifentanil and dexmedetomidine; $\mathrm{T}_{0}$ : before the induction of anesthesia, $\mathrm{T}_{1}: 5 \mathrm{~min}$ after induction of anesthesia, $T_{2}$ : the beginning of operation, $T_{3}$ : during operation, $T_{4}: 6 h$ after surgery, $T_{5}: 12 h$ after surgery. $\mathrm{T}_{6}: 24 \mathrm{~h}$ after surgery. $\mathrm{T}_{7}: 48 \mathrm{~h}$ after surgery. ${ }^{\star} p<0.05$ vs. $\mathrm{T}_{0}{ }^{\#} p<0.05$ vs. $\mathrm{PR}_{2}$ group; ${ }^{\$} p<0.05$ vs. $\mathrm{ER}_{2}$ group

The DBP at different time points in short operation time groups are shown in table 4.1. The DBP were lower at $\mathrm{T}_{1}$ compared to $\mathrm{T}_{0}$ in three groups $(P<0.05)$. The DBP in $\mathrm{ER}_{1}$ and $\mathrm{ERD}_{1}$ group were higher at $\mathrm{T}_{1}$ compared to $\mathrm{PR}_{1}$ group $(P<0.05)$. The $\mathrm{DBP}$ in $\mathrm{ERD}_{1}$ group were lower at $\mathrm{T}_{4}$ compared to $\mathrm{ER}_{1}$ groups $(P<0.05)$, (table 4.1).

Table 4.1 The DBP at $T_{0}, T_{1}, T_{2}, T_{3}, T_{4}, T_{5}, T_{6}$ and $T_{7}$ in short operation time groups. 


\begin{tabular}{|llllll|}
\hline time & $\mathrm{PR}_{1}$ & $\mathrm{ER}_{1}$ & $\mathrm{ERD}_{1}$ & $F$ values & $P$ values \\
& $n=28$ & $n=29$ & $n=32$ & & \\
\hline $\mathrm{T}_{0}$ & $78.4 \pm 5.8$ & $77.6 \pm 6.8$ & $76.4 \pm 6.8$ & 0.76 & 04722 \\
$\mathrm{~T}_{1}$ & $56.1 \pm 5.7 * \$$ & $68.3 \pm 9.8^{*}$ & $67.1 \pm 9.8^{\star \#}$ & 24.92 & 0.000 \\
\hline $\mathrm{T}_{2}$ & $76.9 \pm 6.8$ & $77.1 \pm 7.9$ & $77.9 \pm 6.3$ & 0.29 & 0.7491 \\
\hline $\mathrm{T}_{3}$ & $75.7 \pm 6.7$ & $78.2 \pm 6.3$ & $76.5 \pm 7.1$ & 1.19 & 0.3078 \\
\hline $\mathrm{T}_{4}$ & $85.1 \pm 6.1^{*}$ & $84.9 \pm 6.9 *$ & $80.9 \pm 7.9 * \#$ & 4.22 & 0.0266 \\
\hline $\mathrm{T}_{5}$ & $77.8 \pm 7.7$ & $77.6 \pm 6.4$ & $78.3 \pm 8.1$ & 0.09 & 0.9135 \\
\hline $\mathrm{T}_{6}$ & $78.9 \pm 4.0$ & $78.6 \pm 5.3$ & $76.8 \pm 4.2$ & 1.68 & 0.1924 \\
\hline $\mathrm{T}_{7}$ & $77.6 \pm 4.4$ & $77.8 \pm 5.7$ & $77.3 \pm 5.1$ & 0.13 & 0.883 \\
\hline$F$ values & 55.52 & 10.8 & 9.88 & - & - \\
\hline$P$ values & 0.000 & 0.000 & 0.000 & - & - \\
\hline
\end{tabular}

Values are mean $\pm S D . P R_{1}$ : Propofol-remifentanil; ER 1 : Etomidate-remifentanil; ERD 1 : Etomidateremifentanil and dexmedetomidine; $\mathrm{T}_{0}$ : before the induction of anesthesia, $\mathrm{T}_{1}: 5 \mathrm{~min}$ after induction of anesthesia, $T_{2}$ : the beginning of operation, $T_{3}$ : during operation, $T_{4}: 6 h$ after surgery, $T_{5}: 12 h$ after surgery. $\mathrm{T}_{6}$ : $24 \mathrm{~h}$ after surgery. $\mathrm{T}_{7}: 48 \mathrm{~h}$ after surgery. ${ }^{\star} p<0.05$ vs. $\mathrm{T}_{0} ;{ }^{\#} p<0.05$ vs. $\mathrm{PR}_{1}$ group; ${ }^{\$} p<0.05$ vs. $\mathrm{ER}_{1}$ group

The DBP at different time points in long operation time groups are shown in table 4.2. The DBP were lower at $\mathrm{T}_{1}$ compared to $\mathrm{T}_{0}$ in three groups $(P<0.05)$. The DBP in $\mathrm{ER}_{1}$ and $\mathrm{ERD}_{1}$ group were higher at $\mathrm{T}_{1}$ compared to $\mathrm{PR}_{1}$ group $(P<0.05)$. The $\mathrm{DBP}$ in $\mathrm{ERD}_{1}$ group were lower at $\mathrm{T}_{4}$ compared to $\mathrm{ER}_{1}$ groups $(P<0.05)$, (table 4.2).

Table 4.2 The DBP at $T_{0}, T_{1}, T_{2}, T_{3}, T_{4}, T_{5}, T_{6}$ and $T_{7}$ in long operation time groups. 


\begin{tabular}{|llllll|}
\hline time & $\mathrm{PR}_{2}$ & $\mathrm{ER}_{2}$ & $\mathrm{ERD}_{2}$ & $F$ values & $P$ values \\
& $n=32$ & $n=31$ & $n=28$ & & \\
\hline $\mathrm{T}_{0}$ & $77.2 \pm 7.2$ & $77.6 \pm 9.1$ & $76.8 \pm 6.3$ & 0.09 & 0.911 \\
\hline $\mathrm{T}_{1}$ & $56.5 \pm 7.8^{* \$}$ & $68.1 \pm 6.2^{\star \#}$ & $67.3 \pm 6.7^{\star \#}$ & 24.11 & 0.000 \\
\hline $\mathrm{T}_{2}$ & $77.1 \pm 8.5$ & $76.6 \pm 8.7$ & $77.2 \pm 7.5$ & 0.05 & 0.9471 \\
\hline $\mathrm{T}_{3}$ & $77.6 \pm 6.9$ & $77.9 \pm 9.2$ & $76.8 \pm 7.7$ & 0.25 & 0.783 \\
\hline $\mathrm{T}_{4}$ & $84.2 \pm 6.8^{\star}$ & $85.7 \pm 5.7 *$ & $79.1 \pm 7.2^{\# \$}$ & 2.59 & 0.081 \\
\hline $\mathrm{T}_{5}$ & $77.9 \pm 7.6$ & $77.2 \pm 8.2$ & $77.8 \pm 7.6$ & 0.09 & 0.9097 \\
\hline $\mathrm{T}_{6}$ & $78.7 \pm 5.6$ & $78.8 \pm 5.9$ & $78.4 \pm 3.9$ & 0.06 & 0.9405 \\
\hline $\mathrm{T}_{7}$ & $77.5 \pm 5.8$ & $78.4 \pm 6.8$ & $77.8 \pm 5.3$ & 0.2 & 0.8175 \\
\hline$F$ values & 41.37 & 12.57 & 8.69 & - & - \\
\hline$P$ values & 0.000 & 0.000 & 0.000 & - & - \\
\hline
\end{tabular}

Values are mean $\pm S D$. PR 2 : Propofol-remifentanil; ER : Etomidate-remifentanil; $E_{2} D_{2}$ : Etomidateremifentanil and dexmedetomidine; $\mathrm{T}_{0}$ : before the induction of anesthesia, $\mathrm{T}_{1}: 5 \mathrm{~min}$ after induction of anesthesia, $T_{2}$ : the beginning of operation, $T_{3}$ : during operation, $T_{4}: 6 h$ after surgery, $T_{5}: 12 h$ after surgery. $\mathrm{T}_{6}: 24 \mathrm{~h}$ after surgery. $\mathrm{T}_{7}: 48 \mathrm{~h}$ after surgery. ${ }^{\star} p<0.05$ vs. $\mathrm{T}_{0} ;{ }^{\#} p<0.05$ vs. $\mathrm{PR}_{2}$ group; ${ }^{\$} p<0.05$ vs. $\mathrm{ER}_{2}$ group

The HR at different time points in short operation time groups are shown in table 5.1. The HR were lower at $T_{1}$ and higher at $T_{4}$ compared to $T_{0}$ in three groups $(P<0.05)$. The HR in ERD 1 group were lower at $T_{3}$ and $\mathrm{T}_{4}$ compared to $\mathrm{PR}_{1}$ group and $\mathrm{ER}_{1}$ group $(P<0.05)$, (table 5.1).

Table 5.1 The HR at $T_{0}, T_{1}, T_{2}, T_{3}, T_{4}, T_{5}, T_{6}$ and $T_{7}$ in short operation time groups. 


\begin{tabular}{|llllll|}
\hline time & $\mathrm{PR}_{1}$ & $\mathrm{ER}_{1}$ & $\mathrm{ERD}_{1}$ & $F$ values & $P$ values \\
& $n=28$ & $n=29$ & $n=32$ & & \\
\hline $\mathrm{T}_{0}$ & $79.6 \pm 4.4$ & $78.7 \pm 6.5$ & $77.3 \pm 7.1$ & 1.34 & 0.267 \\
$\mathrm{~T}_{1}$ & $69.3 \pm 5.1^{*}$ & $67.7 \pm 9.1^{*}$ & $66.5 \pm 5.5^{\star}$ & 1.08 & 0.344 \\
$\mathrm{~T}_{2}$ & $78.9 \pm 6.4$ & $77.0 \pm 7.3$ & $76.1 \pm 7.1$ & 0.81 & 0.4478 \\
$\mathrm{~T}_{3}$ & $77.3 \pm 5.7$ & $78.4 \pm 7.6$ & $67.5 \pm 6.9^{*} \#$ & 22.86 & 0.000 \\
$\mathrm{~T}_{4}$ & $84.5 \pm 6.2^{*}$ & $85.3 \pm 4.1^{*}$ & $81.4 \pm 5.9^{*} \#$ & 5.7 & 0.0048 \\
\hline $\mathrm{T}_{5}$ & $78.5 \pm 8.0$ & $78.8 \pm 5.6$ & $78.5 \pm 6.7$ & 0.25 & 0.777 \\
\hline $\mathrm{T}_{6}$ & $80.1 \pm 7.1$ & $78.6 \pm 4.6$ & $79.1 \pm 5.2$ & 1.3 & 0.2787 \\
\hline $\mathrm{T}_{7}$ & $79.1 \pm 5.2$ & $77.4 \pm 5.1$ & $78.4 \pm 4.8$ & 0.64 & 0.5291 \\
\hline$F$ values & 13.43 & 15.37 & 20.74 & - & - \\
\hline$P$ values & 0.000 & 0.0001 & 0.000 & - & - \\
\hline
\end{tabular}

Values are mean $\pm S D$. PR 1 : Propofol-remifentanil; $\mathrm{ER}_{1}$ : Etomidate-remifentanil; ERD 1 : Etomidateremifentanil and dexmedetomidine; $\mathrm{T}_{0}$ : before the induction of anesthesia, $\mathrm{T}_{1}: 5 \mathrm{~min}$ after induction of anesthesia, $T_{2}$ : the beginning of operation, $T_{3}$ : during operation, $T_{4}: 6 h$ after surgery, $T_{5}: 12 h$ after surgery. $\mathrm{T}_{6}: 24 \mathrm{~h}$ after surgery. $\mathrm{T}_{7}: 48 \mathrm{~h}$ after surgery. ${ }^{\star} p<0.05$ vs. $\mathrm{T}_{0} ;{ }^{\#} p<0.05$ vs. $\mathrm{PR}_{1}$ group; ${ }^{\$} p<0.05$ vs. $\mathrm{ER}_{1}$ group

The HR at different time points in long operation time groups are shown in table 5.2. The HR were lower at $T_{1}$ compared to $T_{0}$ in three groups $(P<0.05)$. The HR were higher at $T_{4}$ compared to $T_{0}$ in $\mathrm{PR}_{2}$ group and $\mathrm{ER}_{2}$ group, and lower at $\mathrm{T}_{4}$ compared to $\mathrm{T}_{0}$ in $\mathrm{ERD}_{2}$ group $(P<0.05)$. The $\mathrm{HR}$ in $\mathrm{ERD}_{2}$ group were lower at $\mathrm{T}_{3}$ and $\mathrm{T}_{4}$ compared to $\mathrm{PR}_{2}$ group and $\mathrm{ER}_{2}$ group $(P<0.05)$, (table 5.2).

Table 5.2 The HR at $T_{0}, T_{1}, T_{2}, T_{3}, T_{4}, T_{5}, T_{6}$ and $T_{7}$ in long operation time groups. 


\begin{tabular}{|llllll|}
\hline time & $\mathrm{PR}_{2}$ & $\mathrm{ER}_{2}$ & $\mathrm{ERD}_{2}$ & $F$ values & $P$ values \\
& $n=32$ & $n=31$ & $n=28$ & & \\
\hline $\mathrm{T}_{0}$ & $78.2 \pm 5.6$ & $79.1 \pm 6.2$ & $77.3 \pm 4.5$ & 0.81 & 0.4491 \\
$\mathrm{~T}_{1}$ & $65.7 \pm 7.1^{*}$ & $66.3 \pm 6.0^{*}$ & $67.8 \pm 9.7^{\star}$ & 0.64 & 0.5381 \\
$\mathrm{~T}_{2}$ & $79.4 \pm 6.8$ & $78.1 \pm 7.8$ & $76.7 \pm 6.1$ & 1.1 & 0.3374 \\
$\mathrm{~T}_{3}$ & $77.0 \pm 6.3$ & $77.1 \pm 6.7$ & $67.5 \pm 5.2^{\star} \# \$$ & 22.34 & 0.000 \\
$\mathrm{~T}_{4}$ & $86.7 \pm 4.2^{*}$ & $85.3 \pm 5.2^{*}$ & $73.7 \pm 7.2^{\star} \# \$$ & 46.46 & 0.000 \\
\hline $\mathrm{T}_{5}$ & $79.1 \pm 5.8$ & $79.6 \pm 6.9$ & $78.6 \pm 5.5$ & 0.11 & 0.8975 \\
\hline $\mathrm{T}_{6}$ & $78.3 \pm 5.4$ & $78.5 \pm 4.9$ & $77.8 \pm 6.2$ & 0.09 & 0.9168 \\
\hline $\mathrm{T}_{7}$ & $77.5 \pm 4.9$ & $77.5 \pm 4.1$ & $78.2 \pm 9.1$ & 0.13 & 0.8791 \\
\hline$F$ values & 55.38 & 23.5 & 11.59 & - & - \\
\hline$P$ values & 0.000 & 0.000 & 0.000 & - & - \\
\hline
\end{tabular}

Values are mean $\pm S D$. PR $:$ : Propofol-remifentanil; $\mathrm{ER}_{2}$ : Etomidate-remifentanil; $\mathrm{ERD}_{2}$ : Etomidateremifentanil and dexmedetomidine; $\mathrm{T}_{0}$ : before the induction of anesthesia, $\mathrm{T}_{1}: 5 \mathrm{~min}$ after induction of anesthesia, $T_{2}$ : the beginning of operation, $T_{3}$ : during operation, $T_{4}: 6 h$ after surgery, $T_{5}: 12 h$ after surgery. $\mathrm{T}_{6}: 24 \mathrm{~h}$ after surgery. $\mathrm{T}_{7}: 48 \mathrm{~h}$ after surgery. ${ }^{\star} p<0.05$ vs. $\mathrm{T}_{0} ;{ }^{\#} p<0.05$ vs. $\mathrm{PR}_{2}$ group; ${ }^{\$} p<0.05$ vs. $\mathrm{ER}_{2}$ group

The Serum cortisol concentration at different time points in short operation time groups are shown in table 6.1. The Serum cortisol concentration were lower at $t_{1 \sim 2}$ in ER1 group and $t_{1}$ in $E R D_{1}$ group compared to $\mathrm{t}_{0}$ and $\mathrm{PR}_{1}$ group $(P<0.05)$. The Serum cortisol concentration were higher at $\mathrm{t}_{1} \sim_{2}$ in $\mathrm{ERD}_{1}$ group compared to $\mathrm{ER}_{1}$ group $(P<0.05)$, (table 6.1).

Table 6.1 The Serum cortisol concentration levels at $t_{0}, t_{1}, t_{2}, t_{3}, t_{4}$, and $t_{5}$ in short operation time groups. 


\begin{tabular}{|llllll|}
\hline time & $\mathrm{PR}_{1}$ & $\mathrm{ER}_{1}$ & $\mathrm{ERD}_{1}$ & Fvalues & $P$ values \\
& $n=28$ & $n=29$ & $n=32$ & & \\
\hline $\mathrm{t}_{0}$ & $9.97 \pm 0.58$ & $9.92 \pm 0.56$ & $9.72 \pm 0.57$ & 0.50 & 0.617 \\
$\mathrm{t}_{1}$ & $10.01 \pm 0.54^{\$}$ & $7.17 \pm 0.72^{\star} \#$ & $7.94 \pm 0.61^{*} \#$ & 129.81 & 0.000 \\
$\mathrm{t}_{2}$ & $9.84 \pm 0.44^{\$}$ & $7.96 \pm 0.62^{*} \#$ & $9.72 \pm 0.42^{\$}$ & 125.07 & 0.000 \\
$\mathrm{t}_{3}$ & $9.92 \pm 0.58$ & $9.98 \pm 0.57$ & $9.76 \pm 0.44$ & 0.59 & 0.5587 \\
$\mathrm{t}_{4}$ & $9.96 \pm 0.56$ & $9.87 \pm 0.52$ & $9.80 \pm 0.48$ & 0.23 & 0.7931 \\
$\mathrm{t}_{5}$ & $9.89 \pm 0.57$ & $9.85 \pm 0.51$ & $9.88 \pm 0.51$ & 0.15 & 0.8605 \\
\hline$F$ values & 0.23 & 185.29 & 99.82 & - & - \\
\hline$P$ values & 0.7931 & 0.0001 & 0.000 & - & - \\
\hline
\end{tabular}

Values are mean $\pm S D$. PR 1 : Propofol-remifentanil; ER 1 : Etomidate-remifentanil; ERD ${ }_{1}$ : Etomidateremifentanil and dexmedetomidine; $t_{0}$ : before the induction of anesthesia, $t_{1}: 3 \mathrm{~h}$ after operation, $\mathrm{t}_{2}: 6 \mathrm{~h}$ after operation, $\mathrm{t}_{3}: 24 \mathrm{~h}$ after operation, $\mathrm{t}_{4}: 48 \mathrm{~h}$ after operation, $\mathrm{t}_{5}: 72 \mathrm{~h}$ after operation. ${ }^{*} p<0.05$ vs. $\mathrm{t}_{0} ;{ }^{\#} p<$ 0.05 vs. $\mathrm{PR}_{1}$ group; $\$ p<0.05$ vs. $\mathrm{ER}_{1}$ group

The Serum cortisol concentration at different time points in long operation time groups are shown in table 6.2. The Serum cortisol concentration were lower at $t_{1 \sim 3}$ in $E R_{2}$ group and $t_{1 \sim 2}$ in $E R_{2}$ group compared to $\mathrm{t}_{0}$ and $\mathrm{PR}_{2}$ group $(P<0.05)$. The Serum cortisol concentration were higher at $\mathrm{t}_{1} \sim_{3}$ in $\mathrm{ERD}_{2}$ group compared to $\mathrm{ER}_{2}$ group $(P<0.05)$, (table 6.2).

Table 6.2 The Serum cortisol concentration levels at $t_{0}, t_{1}, t_{2}, t_{3}, t_{4}$, and $t_{5}$ in long operation time groups. 


\begin{tabular}{|llllll|}
\hline time & $\mathrm{PR}_{2}$ & $\mathrm{ER}_{2}$ & $\mathrm{ERD}_{2}$ & $F$ values & $P$ values \\
& $n=32$ & $n=31$ & $n=28$ & & \\
\hline $\mathrm{t}_{0}$ & $9.87 \pm 0.42$ & $9.86 \pm 0.54$ & $10.07 \pm 0.66$ & 1.39 & 0.2542 \\
$\mathrm{t}_{1}$ & $9.92 \pm 0.46^{\$}$ & $5.21 \pm 0.73^{\star \#}$ & $5.73 \pm 0.50^{\star \# \$}$ & 550.84 & 0.000 \\
$\mathrm{t}_{2}$ & $9.86 \pm 0.38^{\$}$ & $5.59 \pm 0.61^{\star \#}$ & $6.37 \pm 0.60^{\star \# \$}$ & 550.12 & 0.000 \\
$\mathrm{t}_{3}$ & $9.90 \pm 0.49^{\$}$ & $7.45 \pm 0.67^{\star \#}$ & $9.71 \pm 0.64^{\$}$ & 147.42 & 0.000 \\
$\mathrm{t}_{4}$ & $9.88 \pm 0.37$ & $9.80 \pm 0.38$ & $9.94 \pm 0.62$ & 0.65 & 0.523 \\
$\mathrm{t}_{5}$ & $9.83 \pm 0.48$ & $9.79 \pm 0.47$ & $10.04 \pm 0.61$ & 1.87 & 0.1237 \\
\hline$F$ values & 0.11 & 451.19 & 343.30 & - & - \\
\hline$P$ values & 0.995 & 0.000 & 0.000 & - & - \\
\hline
\end{tabular}

Values are mean $\pm S D$. $\mathrm{PR}_{2}$ : Propofol-remifentanil; $\mathrm{ER}_{2}$ : Etomidate-remifentanil; $\mathrm{ERD}_{2}$ : Etomidateremifentanil and dexmedetomidine; $t_{0}$ : before the induction of anesthesia, $t_{1}: 3 \mathrm{~h}$ after operation, $\mathrm{t}_{2}: 6 \mathrm{~h}$ after operation, $\mathrm{t}_{3}: 24 \mathrm{~h}$ after operation, $\mathrm{t}_{4}: 48 \mathrm{~h}$ after operation, $\mathrm{t}_{5}: 72 \mathrm{~h}$ after operation. ${ }^{*} p<0.05 \mathrm{vs}$. $\mathrm{t}_{0 ;}{ }^{*} p<$ 0.05 vs. $\mathrm{PR}_{2}$ group; $\$ p<0.05$ vs. $\mathrm{ER}_{2}$ group

The Serum ACTH concentration at different time points in short operation time groups are shown in table 7.1. The Serum ACTH concentration were higher at $t_{1 \sim 2}$ in $E R_{1}$ group and $t_{1}$ in $E R D_{1}$ group compared to $\mathrm{t}_{0}$ and $\mathrm{PR}_{1}$ group $(P<0.05)$. The Serum ACTH concentration were lower at $\mathrm{t}_{1} \sim_{2}$ in $\mathrm{ERD}_{1}$ group compared to $\mathrm{ER}_{2}$ group $(P<0.05)$, (table 7.1$)$.

Table 7.1 The Serum ACTH concentration levels at $t_{0}, t_{1}, t_{2}, t_{3}, t_{4}$, and $t_{5}$ in short operation time groups. 


\begin{tabular}{|llllll|}
\hline time & $\mathrm{PR}_{1}$ & $\mathrm{ER}_{1}$ & $\mathrm{ERD}_{1}$ & $F$ values & $P$ values \\
& $n=28$ & $n=29$ & $n=32$ & & \\
\hline $\mathrm{t}_{0}$ & $4.76 \pm 0.32$ & $4.80 \pm 6.5$ & $4.82 \pm 0.23$ & 1.87 & 0.1597 \\
$\mathrm{t}_{1}$ & $4.83 \pm 0.24^{\$}$ & $6.30 \pm 0.33^{\star \#}$ & $6.08 \pm 0.18^{\star \# \$}$ & 258.08 & 0.000 \\
$\mathrm{t}_{2}$ & $4.81 \pm 0.22^{\$}$ & $5.71 \pm 0.38^{* \#}$ & $4.90 \pm 0.19^{\$}$ & 320.82 & 0.000 \\
$\mathrm{t}_{3}$ & $4.83 \pm 0.19$ & $4.84 \pm 0.16$ & $4.85 \pm 0.13$ & 0.12 & 0.000 \\
$\mathrm{t}_{4}$ & $4.82 \pm 0.24$ & $4.82 \pm 0.18$ & $4.82 \pm 0.12$ & 0.06 & 0.9383 \\
$\mathrm{t}_{5}$ & $4.78 \pm 0.20$ & $4.77 \pm 0.17$ & $4.84 \pm 0.15$ & 1.34 & 0.2685 \\
\hline$F$ values & 0.23 & 143.45 & 219.41 & - & - \\
\hline$P$ values & 0.9674 & 0.000 & 0.000 & - & - \\
\hline
\end{tabular}

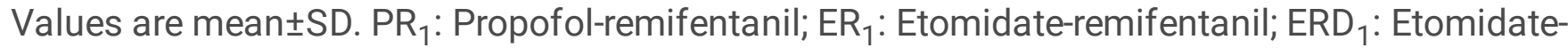
remifentanil and dexmedetomidine; $\mathrm{t}_{0}$ : before the induction of anesthesia, $\mathrm{t}_{1}: 3 \mathrm{~h}$ after operation, $\mathrm{t}_{2}: 6 \mathrm{~h}$ after operation, $\mathrm{t}_{3}$ : $24 \mathrm{~h}$ after operation, $\mathrm{t}_{4}: 48 \mathrm{~h}$ after operation, $\mathrm{t}_{5}: 72 \mathrm{~h}$ after operation. ${ }^{*} p<0.05 \mathrm{vs}$. $\mathrm{t}_{0} ;{ }^{*} p<$ 0.05 vs. $\mathrm{PR}_{1}$ group; $\$ p<0.05$ vs. $\mathrm{ER}_{1}$ group

The Serum ACTH concentration at different time points in long operation time groups are shown in table 7.2. The Serum $A C T H$ concentration were higher at $t_{1 \sim 3}$ in $E_{2}$ group and $t_{1 \sim 2}$ in $E_{2} D_{2}$ group compared to $\mathrm{t}_{0}$ and $\mathrm{PR}_{2}$ group $(P<0.05)$. The Serum ACTH concentration were lower at $\mathrm{t}_{1} \sim_{3}$ in $\mathrm{ERD}_{2}$ group compared to $\mathrm{ER}_{2}$ group $(P<0.05)$, (table 7.2$)$.

Table 7.2 The Serum ACTH concentration levels at $t_{0}, t_{1}, t_{2}, t_{3}, t_{4}$, and $t_{5}$ in long operation time groups. 


\begin{tabular}{|llllll|}
\hline time & $\mathrm{PR}_{2}$ & $\mathrm{ER}_{2}$ & $\mathrm{ERD}_{2}$ & $F$ values & $P$ values \\
& $n=32$ & $n=31$ & $n=28$ & & \\
\hline $\mathrm{t}_{0}$ & $4.82 \pm 0.17$ & $4.78 \pm 0.24$ & $4.81 \pm 0.18$ & 0.20 & 0.8183 \\
$\mathrm{t}_{1}$ & $4.78 \pm 0.17^{\$}$ & $6.24 \pm 0.15^{\star \#}$ & $6.07 \pm 0.19^{\star \# \$}$ & 628.78 & 0.000 \\
$\mathrm{t}_{2}$ & $4.81 \pm 0.13^{\$}$ & $5.85 \pm 0.22^{\star \#}$ & $5.52 \pm 0.17^{* \# \$}$ & 733.28 & 0.000 \\
$\mathrm{t}_{3}$ & $4.82 \pm 0.11^{\$}$ & $5.48 \pm 0.16^{\star \#}$ & $4.82 \pm 0.13^{\$}$ & 228.03 & 0.000 \\
$\mathrm{t}_{4}$ & $4.83 \pm 0.10$ & $4.81 \pm 0.15$ & $4.81 \pm 0.11$ & 0.19 & 0.8307 \\
\hline $\mathrm{t}_{5}$ & $4.80 \pm 0.13$ & $4.77 \pm 0.18$ & $4.78 \pm 0.10$ & 0.36 & 0.6695 \\
\hline$F$ values & 0.30 & 267.59 & 252.46 & - & - \\
\hline$P$ values & 0.9364 & 0.000 & 0.000 & - & - \\
\hline
\end{tabular}

Values are mean $\pm S D$. PR 2 : Propofol-remifentanil; $\mathrm{ER}_{2}$ : Etomidate-remifentanil; $\mathrm{ERD}_{2}$ : Etomidateremifentanil and dexmedetomidine; $t_{0}$ : before the induction of anesthesia, $t_{1}: 3 \mathrm{~h}$ after operation, $t_{2}: 6 \mathrm{~h}$ after operation, $\mathrm{t}_{3}: 24 \mathrm{~h}$ after operation, $\mathrm{t}_{4}: 48 \mathrm{~h}$ after operation, $\mathrm{t}_{5}: 72 \mathrm{~h}$ after operation. ${ }^{\star} p<0.05$ vs. $\mathrm{t}_{0} ;{ }^{\#} p<$ 0.05 vs. $\mathrm{PR}_{2}$ group; $\$ p<0.05$ vs. $\mathrm{ER}_{2}$ group

\section{Figures}




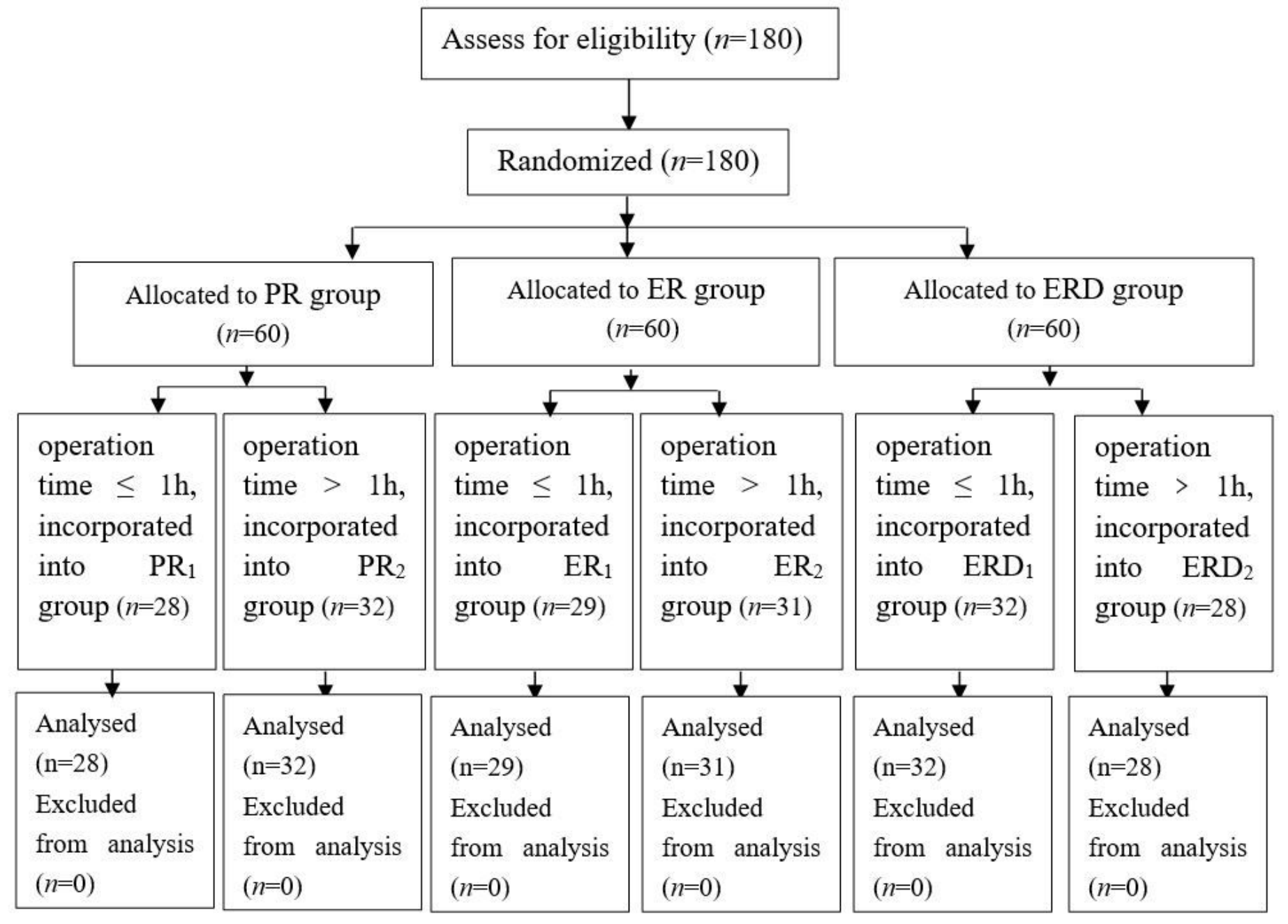

Figure 1

Study flow diagram One hundred and eighty patients were screened for eligibility, and subsequently allocated to three groups. No patient dropped out of the trial. A total of one hundred and eighty patients completed the study (Fig. 1). 